\begin{tabular}{|l|l|l||}
\hline \multicolumn{2}{|c|}{ PublisherInfo } \\
\hline \hline PublisherName & $:$ & BioMed Central \\
\hline \hline PublisherLocation & $:$ & London \\
\hline \hline PublisherImprintName & $:$ & BioMed Central \\
\hline \hline
\end{tabular}

\title{
The effect of thoracocentesis on lung function and transthoracic electrical bioimpedence
}

\begin{tabular}{|l|l|l||}
\hline \multicolumn{2}{|c||}{ ArticleInfo } \\
\hline \hline ArticleID & $:$ & 4089 \\
\hline \hline ArticleDOI & $:$ & $10.1186 /$ ccf-1999-141 \\
\hline \hline ArticleCitationID & $:$ & 141 \\
\hline \hline ArticleSequenceNumber & $:$ & 26 \\
\hline \hline ArticleCategory & $:$ & Paper Report \\
\hline ArticleFirstPage & $:$ & 1 \\
\hline \hline ArticleLastPage & $:$ & 4 \\
\hline \hline & & RegistrationDate : 1999-5-7 \\
ArticleHistory & $:$ & OnlineDate $:$ 1999-5-7 \\
\hline \hline ArticleCopyright & $:$ & Current Science Ltd1999 \\
\hline \hline ArticleGrants & $:$ & \\
\hline \hline ArticleContext & $:$ & 130541111 \\
\hline \hline
\end{tabular}




\section{Keywords}

Pulmonary function, thoracocentesis, transthoracic electrical bioimpedence

\section{Comments}

Potential sources of error in this study are that the conclusions drawn about changes in baseline impedance between the cardiac and malignancy groups may simply reflect the different male to female ratios of the groups. Additionally, changes in spirometric values may have been improved by familiarity with the technique, rather than demonstrating a true improvement. This paper suggests that thoracocentesis does bring about a useful increase in lung volumes, however it is worth noting one significant pneumothorax amongst the group of 16 patients.

\section{Introduction}

This study assessed the change in measured respiratory function [forced expiratory volume in $1 \mathrm{~s}$ (FEV1), forced vital capacity (FVC), total lung capacity (TLC) and lung diffusion capacity (DLCO)] and in transthoracic electrical bioimpedence (TEB) after thoracocentesis. The study group comprised 15 patients with pleural effusions due to malignant or cardiac disease. The patients in the study were not on intensive care but useful information can be obtained for the change in pulmonary function tests (PFTs) brought about after thoracocentesis.

\section{Aims}

To determine the relationship between improvement in lung function and changes in TEB after thoracocentesis in patients with pleural effusions.

\section{Methods}


Sixteen patients were recruited for the study, one of whom was withdrawn due to the development of a pneumothorax during thoracocentesis. Seven had effusions secondary to cardiac disease (male:female 1:6) and nine malignant disease (male:female 4:5). Thoracocentesis was performed with the patient sitting with a needle inserted blindly through the eighth or ninth interspace. Aspiration was continued until no more fluid was forthcoming or chest pain or coughing occurred. TEB analysis was made after every $500 \mathrm{ml}$ aspirated. PFTs were measured prior to, and 1-2 $\mathrm{h}$ post, thoracocentesis. The highest of two values (within 3\%) were taken as the final result. TLC and DLCO were measured with a single breath technique after inhalation of gas containing carbon monoxide and helium. Changes in TEB, mean arterial pressure (MAP), blood pressure (BP) and PFTs before and after thoracocentesis were compared using the Wilcoxon's non-parametric test for paired data.

\section{Results}

The median volume of fluid aspirated was $1250 \mathrm{ml}$ (325-2300) with symptomatic relief of dyspnoea in all patients. Cardiovascular variables were largely unchanged by thoracocentesis; systolic and MAPs showed a statistically significant but clinically insignificant decrease. Cardiac output as estimated by changes in TEB remained unchanged. Pulmonary function tests and DLCO increased by 5.5 to $18 \%$ over baseline values. FEV1 and FVC increased in a linear fashion with the amount of fluid aspirated. Baseline impedance also changed with the volume aspirated, suggesting that this may have some value as a noninvasive way of assessing the amount of fluid within the thorax.

\section{Discussion}

The usefulness of TEB in assessing the change in intrathoracic fluid may well be limited, especially in intensive care unit (ICU) patients. In this study the authors found that patients with cardiac disease showed relatively less change in baseline impedance, presumably because of the increased fluid in the pulmonary vascular bed. There was a trend towards a greater improvement of DLCO and TLC in patients with effusions over $1000 \mathrm{ml}$.

\section{Additional information}

This paper provides a concise overview of the principles of transthoracic electrical bioimpedence. 


\section{References}

1. Zrahn B, Vittrup Jensen B, Olsen F, Roland Petersen J, Kanstrup I-L: The effect of thoracocentesis on lung function and transthoracic electrical bioimpedence. Respir Med. 1999, 93: 196-201

This PDF file was created after publication. 